\title{
DEMOGRAPHIC AND CLINICAL CHARACTERISTICS OF ALCOHOL USE DISORDER IN PATIENTS UNDERGOING BARIATRIC SURGERY
}

19.1 WPA WORLD

CONGRESS OF PSYCHIATRY

M. Oscoz-Irurozqui ${ }^{1}$, S. Llebot ${ }^{1}$, G. Adam¹, M.D. Moreno', L. Yuguero'.

1Benito Menni CASM, Centro de Atención y Seguimiento a las drogodependencias, L'Hospitalet de Llobregat, Spain.

\section{Background:}

- Recent reviews suggest that a significant proportion of patients undergoing bariatric surgery (BS) develop postoperative problems of alcohol $(\mathrm{OH})$ use'1.

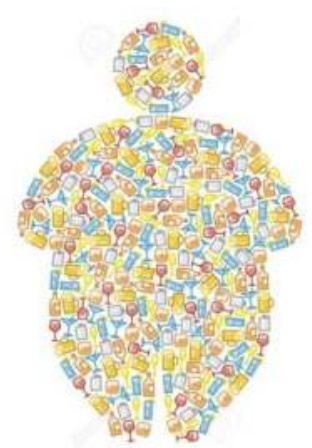

- However, few studies have analyzed characteristics, patterns of consumption and possible risk factors of this population.

\section{Materials and methods:}

It is a descriptive study of 11 patients (63.64\% women) undergoing bariatric surgery (mean age in surgery 43 years), which perform ambulatory monitoring in a drug addiction center (Table 1).

The information is obtained retrospectively through the review of clinical histories.

Percentages are obtained with Excel

\section{Objectives:}

To evaluate demographic and clinical variables in patients with a history of bariatric surgery who have an alcohol use disorder (AUD), specifically:

1. Consumption severity,

2. Psychiatric comorbidity

3. Type of surgical intervention

4. Temporal relationship between surgery and AUD onset

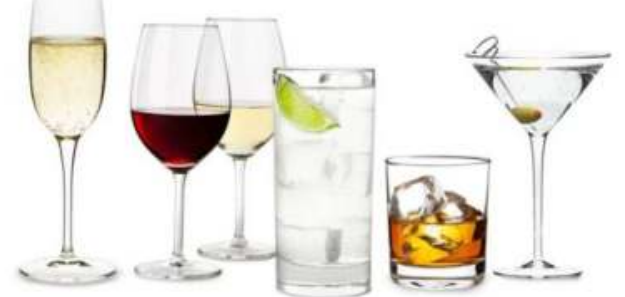

\section{Results:}

- Most common modalities of surgery are vertical gastroplasty and Roux-Y bypass (36.36\% both).

- AUD was established after surgery in $45.46 \%$ of patients (mean time 3.6 years later).

- Diagnosis of alcohol abuse is the most frequent (54.55\%; mean consumption $161.8 \mathrm{~g}$ alcohol/day).

- Other psychiatric diagnoses also appear in $81.82 \%$ of the sample, and the unspecified adjustment disorder is the most prevalent (33.33\%).

Table 1. Clinical characteristics of patients of the sample.

\begin{tabular}{|c|c|c|c|c|c|c|c|c|}
\hline Sex & Patient origin & Age BS & BS type & Consume start & g OH/day (máx.) & Other drugs & Diagnosis $\mathrm{OH}$ & Other diagnosis \\
\hline Female & Day hospital & 35 & Roux-en-Y bypass & 20 & 120 & No & Abuse & $\begin{array}{c}\text { Adjustment disorder, fibromyalgia, chronic } \\
\text { fatigue }\end{array}$ \\
\hline Female & Primary care & 39 & Roux-en-Y bypass & 6 & 150 & Cannabis, cocaine & Moderate dependency & No \\
\hline Female & Primary care & 32 & Roux-en- $Y$ bypass & 15 & 120 & Cannabis, cocaine & Moderate dependency & Cocaine dependence \\
\hline Female & Primary care & 56 & Sleeve gastrectomy & "chilhood" & 10 & No & Mild dependency & Adjustment disorder \\
\hline Female & & 44 & Roux-en- $Y$ bypass & 46 & 50 & No & Abuse & Depressive disorder \\
\hline Female & Mental health center & 60 & Sleeve gastrectomy & 15 & 280 & Tobacco & Severe dependency & Depressive disorder \\
\hline Female & CSMA (OH) & 61 & Sleeve gastrectomy & 23 & 300 & No & Abuse & No \\
\hline Male & Primary care & 52 & Roux-en-Y bypass & "adolescence" & 60 & No & Abuse & No \\
\hline Male & Primary care & 33 & Sleeve gastrectomy & 18 & 60 & Cocaine & Abuse & Adjustment disorder \\
\hline Male & Hospitalization & 35 & Gastric balloon & 13 & 300 & $\begin{array}{l}\text { Tobacco, cocaine, heroine, } \\
\text { hallucinogens }\end{array}$ & Abuse & Cocaine dependence, personality disorder \\
\hline Male & Primary care & 26 & Sleeve gastrectomy & 14 & 240 & Cannabis, cocaine & Moderate dependency & Cocaine abuse \\
\hline
\end{tabular}

\section{Conclusions:}

$\checkmark$ Predominance of post-surgical diagnosis of abuse of alcohol as compared with dependence, as well as the finding of a relatively low intake of this substance suggest us that anatomical and functional changes post-surgery are in relation with alterations in the metabolism of the toxic, that is worse tolerated.

$\checkmark$ Results should be taken into account regarding pre and post-surgical prevention, and also in the intervention. However, further research is required to elucidate risk factors for the development of AUD post-bariatric surgery. 